\title{
Reflexão sobre as diretrizes da educação moderna e pós-moderna no ensino de língua estrangeira
}

\author{
Andréia Matias Azevedo 1 \\ Márcia Atálla Pietroluongo ${ }^{2}$
}

Resumo: Este estudo versará sobre o espaço reservado à teoria e à prática no ensino-aprendizagem de língua estrangeira (LE), em particular de Francês língua estrangeira (FLE), tendo como principal objetivo analisar o nível de relação dessas atividades nesse campo e verificar se as orientações multi/pluri/trans/interdisciplinares favorecem, de fato, que os sujeitos tenham uma formação mais complexa e menos fragmentada, como preconizam certos especialistas do campo da educação e da Organização das Nações Unidas para a Educação, a Ciência e a Cultura (Unesco).Atualmente, convém destacar que o papel do professor parece se limitar a uma prática mecânica e a-histórica do conhecimento, destituindo-o, assim, cada vez mais de sua imagem de intelectual crítico no contexto social. Para confirmar ou refutar tal hipótese, serão apresentadas as concepções de alguns especialistas da educação e do ensino de línguas relacionadas com essa temática, com base notadamente nas teorias de Luis Paulo da Moita Lopes (1969), José Carlos P. de Almeida Filho (1999, 2008), Newton Duarte (2000), José Libâneo (2009) e Glaudêncio Frigotto (2011).

Palavras-chave: Teoria. Prática.Professor.Intelectual crítico.

\section{Réflexion sur les orientations de l'education moderne et post-moderne dans l'enseignement de langue etrangère}

Résumé : Cette étude portera sur l'espace réservé à la théorie et à la pratique dans l'enseignement-apprentissage de langue étrangère (LE), en particulier de Francês langue étrangère (FLE), ayant comme principal objectif analyser le niveau de relation de ces activités dans ce domaine et vérifier si les orientations multi/trans/interdisciplinaires favorisent, en fait, chez les sujets une formation plus complexe et moins fragmentée, comme le prétendent certains experts du domaine éducatif et de l'Organisation des Nations Unies pour l'éducation, la science et la culture (Unesco).À nos jours, il faut noter que le rôle de l'enseignant semble se limiter à une pratique mécanique et anhistorique, en le destituant, ainsi,de plus en plus, de son image d'intellectuel critique dans le contexte social où il vit. Pour confirmer ou réfuter ces hypothèses, les conceptions de certains spécialistes de l'éducation et de l'enseignement de langues concernant ce sujet seront présentées, sur la base notamment des théories de Luis Paulo da Moita Lopes (1996), José Carlos P. de Almeida Filho(2008), Newton Duarte (2000), José Libâneo (2009) e Glaudêncio Frigotto (2011).

Mots-clés:Théorie.Pratique. Enseignant.Intellectuel critique.

\section{Introdução}

\footnotetext{
${ }^{1}$ Doutoranda da Universidade Federal do Rio de Janeiro pelo Programa de Pós-graduação em Letras Neolatinas (Estudos Neolatinos — Opção: Língua Francesa). E-mail: deiamatias@ig.com.br, telefone: 988831231

2 É Professora Titular do Programa de Pós-Graduação em Letras Neolatinas da Universidade Federal do Rio de Janeiro. Possui Licenciatura em Letras - Português/ Francês pela Universidade Santa Úrsula, Mestrado e Doutorado em Letras Neolatinas - Língua Francesa e Literaturas de Língua Francesa (UFRJ), Pós-Doutorado no PGET (UFSÇ).
} 
Este artigo vai tratar, no primeiro tópico, da teorização da prática do professor com o advento do cientificismo e da perda de sua autonomia no processo de ensino-aprendizagem de língua estrangeira (LE). Serão também discutidas as ideologias subjacentes ao conceito de professor reflexivo e explicitadas as considerações de alguns especialistas sobre a formação dos futuros professores.

O segundo tópico versará sobre as pesquisas de natureza interdisciplinar, a fim de verificar se elas permitem, de fato, uma apreensão mais complexa do conhecimento, como defendem determinados pensadores da pós-modernidade. Todavia, antes de adentrar tal questão, este artigo vai apresentar as diferenças entre os conceitos de multi/pluri/trans/interdisciplinaridade.

Quanto à relevância deste estudo para o campo, o interesse é propor uma reflexão sobre o espaço da teoria e da prática no ensino de FLE, bem como avaliar o papel do professor de tecnicista e de intelectual no processo de ensino-aprendizagem. Importa dizer que a apresentação de concepções divergentes sobre a interdisciplinaridade tem como propósito analisá-la de maneira mais realista, identificando suas vantagens e seus limites no processo investigativo.

\section{O grau de interação e dissonância entre teoria e prática no universo de LE}

É imprescindível destacar, inicialmente, que o ensino de LE por volta da década de 1950 passou a se pautar, em especial, pelos critérios da produção e da socialização do conhecimento científico. No século XX, Galisson e Puren (2001) mencionam o aparecimento de três disciplinas vinculadas ao ensino de línguas: a linguística aplicada (LA), que nasceu nos Estados Unidos no período da Segunda Guerra Mundial, mais voltada para o ensino do inglês; a didática das línguas (DL), surgida posteriormente, nos anos 1970, que coloca no centro de suas reflexões o sujeito (aluno); e, nos anos 1980, o advento da didactologia das línguas-culturas (DLC), cujo objetivo principal é relacionar as práticas pedagógicas com as teorias.

Com base na psicologia behaviorista e na linguística estruturalista, estudiosos interessados no ensino-aprendizagem de LE, como Leonard Bloomfield, elaboraram a metodologia áudio-oral (MAO), que representou uma ruptura com as metodologias precedentes em virtude de sua natureza científica. Já a LA proveio da linguística teórica, mas se distinguiu por se ater ao ensinoaprendizagem de LE. Posteriormente, enveredou por analisar a língua em uso em outros 
contextos sociais. Cabe dizer que esse tipo de metodologia indutiva era realizada também em outros campos, como a antropologia e a semiótica (MOITA LOPES, 1996).

No que diz respeito às grandes contribuições iniciais da LA para o ensino de LE, Moita Lopes (1996) destaca o estudo do erro e, posteriormente, o conceito de interlíngua, uma língua intermediária, construída pelo aprendiz no processo de ensino-aprendizagem, apresentando características da língua de partida e da língua de chegada, mas permitindo a interação com os falantes do idioma aprendido.

Sob esse paradigma ideológico, a partir da década de 1960, as formações de professores passam a se centrar, em geral, no "como" fazer, em detrimento de "o que" e "para que" fazer. No âmbito do ensino de LE, o domínio linguístico da língua ensinada, das orientações propostas nos métodos e dos suportes didáticos, como fita-cassete e vídeos, passa a ser o parâmetro para o julgamento da competência do professor.

No que tange à aquisição de uma língua, é importante lembrar a existência de três teorias. A behaviorista, na qual o aprendizado humano depende, sobretudo, de estímulos, condicionamento de hábitos e ações externas; a gerativista, que se opôs à primeira sob o argumento de que as crianças já nascem com uma predisposição para aprender, pois são capazes de produzir e de criar novas sentenças;e a interacionista, cujos teóricos contestam as posições precedentes asseverando que o aprendizado se constrói por meio da interação entre o indivíduo e a sociedade.

Figueiredo faz esta análise:

Em síntese, na visão interacionista, a língua materna é vista como um produto da atividade social, determinado cultural e historicamente, e um processo de interação das crianças com os membros de sua comunidade. Ela não é uma forma de comportamento, nem tampouco uma faculdade inata que capacita as crianças a adquirir somente a competência linguística.(FIGUEIREDO, 1997, p. 24)

Na década de 1980, os pesquisadores da LA e outros estudiosos interessados pelo ensino de línguas se voltam para a questão da interação, dos processos sociointeracionais e dos estudos sociocognitivos, com base na concepção de que todo conhecimento cultural se constrói no contexto social.Todavia, Duarte (2000) sinaliza que esse conhecimento passa a ter como referente a realidade dos sujeitos, excluindo a referência histórica.Com efeito, o aspecto cultural é 
abordado a partir de uma lógica pragmática, deixando de lado uma abordagem do sujeito de caráter filosófico.

Sobre o construtivismo piagetiano, pelo qual as novas orientações passam a se calcar no final do século XX, Duarte se apropria desta enunciação de Ernest von Glasersfeld:

A ideia-chave que separa o construtivismo de outras teorias da cognição foi lançada há aproximadamente 60 anos por Jean Piaget. Trata-se da ideia de que o que chamamos de conhecimento não tem, e não pode ter, o propósito de produzir representações de uma realidade independente, mas antes tem uma função adaptativa. Esta mudança na avaliação da atividade cognitiva acarreta um irrevogável rompimento com a tradição epistemológica geralmente aceita na civilização ocidental, de acordo com a qual o conhecedor deve se esforçar para atingir uma visão do mundo real. Embora neste século as revoluções nas ciências físicas tenham conduzido à aceitação de que tal visão parece impossível, mesmo de acordo com a teoria física, a maioria dos filósofos atémse à crença de que o progresso da ciência, de alguma forma, conduzirá a uma aproximação da verdade definitiva. (VON GLASERSFELD, 1998, p.19 apud DUARTE, 2000, p.107)

Sobre a psicologia cognitiva, Libâneo (2002) acrescenta que o construtivismo piagetiano se desenvolveu como uma forma de reflexividade que governa o "eu" por meio de uma autonomia, de uma liberdade que o torna submisso aos controles sociais por seu egocentrismo. Ao acreditar que o acesso à realidade depende, sobretudo, de sua análise reflexiva, o sujeito se aliena do mundo e de si mesmo.

Na década de 1990, com o suporte das pesquisas científicas realizadas no campo da linguística, da LA, da pragmática, da psicologia e da pedagogia, surgiram no ensino de LE as formações com objetivo específico, denominadas FOS no ensino de Francês língua estrangeira (FLE), com a finalidade de oferecer aos sujeitos competências que fossem ao encontro de suas reais necessidades de trabalho e de estudo. Com efeito, muitos professores passaram a se especializar em determinado "segmento". Por exemplo, dedicaram-se à tradução no ensino de LE, produção oral e escrita e, por conseguinte, se afastaram muitas vezes do processo de aprendizado do aluno como um todo, deixando de ser um artesão, que conhece todas as etapas de seu ofício, para se tornar um operário, que se detém em realizar uma função específica. Segundo Luis Porcher (CUQ; GRUGA, 2002), a proposta de formação específica teve como principal obstáculo a dificuldade de os professores identificarem as necessidades linguísticas dos aprendizes, formularem os objetivos da aprendizagem e definirem os conteúdos. 
Cabe elucidar que o século XX foi marcado pela economia fordista, que se caracterizou pela produção em série. Contudo, na década de 1970 o mercado vivenciou o toyotismo, que demandava dos sujeitos competências relacionadas com uma produção mais flexível, o saberfazer, um conhecimento mais teórico de sua prática. De acordo com Libâneo (2000), a sociedade pós-industrial se distinguiu da primeira por apresentar um consumismo especializado e, por sua vez, por exigir dos sujeitos um conhecimento também especializado.

Analisando as diretrizes educativas e o contexto político-econômico-social, observa-se que as ideologias do mercado foram aportadas para a educação. Tais observações se confirmam com o Relatório para a Unesco da Comissão Internacional sobre Educação para o Século XXI.

$\mathrm{Na}$ indústria, especialmente para os operadores e os técnicos, o domínio do cognitivo e do informativo nos sistemas de produção torna um pouco obsoleta a noção de qualificação profissional e leva a que se dê muita importância à competência pessoal. O progresso técnico modifica, inevitavelmente, as qualificações exigidas pelos novos processos de produção. As tarefas puramente físicas são substituídas por tarefas de produção mais intelectuais, mais mentais, como o comando de máquinas, a sua manutenção e vigilância, ou por tarefas de concepção, de estudo, de organização à medida que as máquinas se tornam, também, mais "inteligentes" e que o trabalho se "desmaterializa".(2000, p. 9394)

Com o surgimento das DLCs, pesquisadores franceses como Galisson e Puren(2001) enfatizam a importância de que o professor se torne mais autônomo, que ele mesmo construa seu próprio material. No entanto, advertem que isso reivindica o saber teorizar sobre uma problemática com a qual o professor possa se confrontar em sua prática. Em outros termos, ele deve agir como um pesquisador que procura descrever, analisar, interpretar e conceituar seu objeto de estudo.

De acordo com Duarte e Libâneo, na década de 1990 a abordagem de formação de professores denominada Professor Reflexivo se embasava exatamente nesses princípios descritos por Puren e Galisson. No primeiro momento, tem-se a impressão de que há uma ruptura com a epistemologia da prática; porém, ao fazer uma análise mais detalhada, o professor se dá conta de que a teoria está atrelada, sobretudo, à sua prática, a um saber-fazer.

Sobre o conceito de um professor crítico, Libâneo profere que

A meu ver, os professores deveriam desenvolver simultaneamente três capacidades: a primeira, de apropriação teórico-crítica das realidades em questão 
considerando os contextos concretos da ação docente; a segunda, de apropriação de metodologias de ação, de formas de agir, de procedimentos facilitadores do trabalho docente e de resolução de problemas de sala de aula. O que destaco é a necessidade da reflexão sobre a prática a partir da apropriação de teorias como marco para as melhorias das práticas de ensino, em que o professor é ajudado a compreender o seu próprio pensamento e a refletir de modo crítico sobre sua prática e, também, a aprimorar seu modo de agir, seu saber-fazer, internalizando também novos instrumentos. A terceira é a consideração dos contextos sociais, políticos, institucionais na configuração das práticas escolares. (LIBÂNEO, 2002, p. 70)

Nessa mesma linha de pensamento de Libâneo, Contreras enfatiza a importância de fazer uma reflexão sobre o contexto político-econômico-social na atividade do docente, dizendo que:

Tratar-se-ia é de perguntar se é possível conceber a reflexão como um processo que incorpore a consciência sobre as implicações sociais, econômicas e políticas da prática do ensino, para poder superar visões reducionistas da reflexão que não transcendam as implicações mais imediatas da ação em sala de aula, ou com o objetivo de evitar a absorção por retóricas de maior responsabilização sem aumentar a capacidade de decisão. (CONTRERAS, 1997, p. 139)

Para alguns especialistas, como Philippe Perrenoud (1999), e os elaboradores de orientações didáticas e pedagógicas, a formação do professor deve ser de caráter tecnicista. Alegam que a formação teórica proposta nas universidades não contribuiu para a realidade do professor. Infelizmente, essa concepção vem tendo peso no espaço educativo. Muitos educadores e professores reproduzem esses discursos sem refletir que com isso cada vez mais permitem que outros lhes ditem, prescrevam o certo e o errado, destituindo-os do papel de intelectual no espaço social.

Neste trecho, Perrenoud torna explícito que a formação por competência se pauta também pela prática:

A formação de competências exige uma pequena revolução cultural para passar de uma lógica do ensino para uma lógica do treinamento, baseada em um postulado relativamente simples: constroem-se as competências exercitando-se em situações complexas. (PERRENOUD, 1999, p.54)

É importante destacar que as ideias do teórico francês Philippe Perrenoud sobre o ensinoaprendizagem por competências teve forte impacto no ensino de FLE. Em centros de língua, muitos professores passaram a ser orientados a precisar o saber-fazer que os alunos devem 
apreender em cada aula para trabalhar, estudar e viver no exterior. Cabe dizer que tal proposta parece se centrar no resultado e desconsiderar que o conhecimento precisa de tempo para se sedimentar.

Libâneo (2000) assinala que a proposta de reflexividade de Paulo Freire se assenta no processo da ação-reflexão-ação e na consciência política. Comenta que o "método Paulo Freire" propõe que o professor se afaste, inicialmente, do contexto concreto para que consiga ter uma análise mais crítica dos fatos por meio de uma decodificação das situações existenciais, que serão confrontadas, posteriormente, com a decodificação do diálogo realizado entre educador e educandos.

No contexto concreto somos sujeitos e objetos em relação dialética com o objeto; no contexto teórico assumimos o papel de sujeitos cognoscentes da relação sujeito-objeto que se dá no contexto concreto para, voltando a este, melhor atuar como sujeitos em relação ao objeto. Estes momentos constituem a unidade [...] da prática e da teoria, da ação e da reflexão. [...] A reflexão só é legítima quando nos remete sempre [...] ao concreto, cujos fatos busca esclarecer, tornando assim possível nossa ação mais eficiente sobre eles. Iluminando uma ação exercida ou exercendo-se, a reflexão verdadeira clarifica, ao mesmo tempo, a futura ação na qual se testa e que, por sua vez, se deve dar a uma nova reflexão. (FREIRE, 1976, p.135 apud LIBÂNEO, 2000, p.58)

Libâneo conclui salientando que existem dois tipos de reflexividade:a de cunho neoliberal, que se apoia na ideologia (neo)positivista, na racionalidade instrumental, e a de cunho crítico, que discute a reflexividade crítica, crítico-reflexiva, reconstrucionista social, comunicativa, hermenêutica. $\mathrm{O}$ autor acrescenta ainda que determinadas concepções do professor reflexivo aportam temas do "pensamento pós-moderno".

Apesar de todas as críticas sobre a formação do professor, Moita Lopes (1996) se mostra um pouco mais otimista com relação ao futuro do ensino-aprendizagem de línguas, pois constata a existência de um movimento que denomina professor-pesquisador. Isso significa que o professor vem deixando de exercer somente o "papel de cliente/consumidor" (p. 89) e está procurando assumir uma atuação investigativa e crítica. Em sua leitura, essa tendência aponta para uma necessidade do próprio educador de ter um melhor domínio sobre a sala de aula, mas também ele enxerga esse fato como uma forma de avanço educacional.

Almeida Filho (2009), entretanto, adverte que ainda há poucos professores que voltam à universidade. Reconhece, porém, que ser pesquisador exige, em específico, saber pesquisar, ler e 
discutir sobre as recentes investigações. Todavia, conforme Moita Lopes (1996), o pós-graduado em Letras atuará diferentemente e, por conseguinte, mexerá com o cenário escolar. Cabe dizer que uma das fortes críticas à LA está atrelada, ainda, à distância existente entre a academia e as aulas de língua.

\section{As ideologias implícitas em torno do multi/pluri/trans/interdisciplinar e do aprender a aprender}

Fazendo uma breve contextualização dos modos de apreensão e de transmissão do conhecimento, convém ressaltar que a concepção positivista teve seu auge no século XIX com o sociólogo francês Augusto Comte, que via o método científico como o único meio confiável para se chegar à verdade. Além disso, os positivistas pregavam que o progresso do Estado, do sistema capitalista e da sociedade dependia de leis e de ações que garantissem a ordem social. Essa concepção de organicidade e categorização foi incorporada em diversos domínios. No âmbito do saber, com o intuito de melhor apreendê-lo, as ciências foram divididas em disciplinas; na esfera do trabalho, a fragmentação da produção contribuiu para o aumento da produtividade; na educação, o ato de educar passou a ser um dever das sociedades modernas, e o de aprender, um direito do cidadão (IMBERNÓN, 1999).

No que diz respeito ao discurso contra a disciplina, a especialização, e a favor da multi/pluri/trans/interdisciplinaridade, é necessário verificar que subjacente a esta posição existem muitas vezes ataques às pesquisas científicas. As principais críticas que lhe são lançadas devem-se a seu rigor metodológico para tratar da realidade e dos sujeitos e ao tratamento descontextualizado dos fatos, desconsiderando que eles funcionam, em geral, interligados, integrados e em função de dada realidade. Com relação aos defensores da interdisciplinaridade, convém mencionar que é possível constatar três tipos de vertentes: a humanista, a crítico-social e a vertente da complexidade.

No entanto, antes de discorrer sobre as vertentes interdisciplinares, é essencial estabelecer as diferenças entre os conceitos de multidisciplinar, pluridisciplinar, transdisciplinar e interdisciplinar, tão citados no atual contexto. Valer dizer que há muita polêmica sobre o modo de conceituá-los. Todavia, muitos estudiosos concordam com o fato de que a interdisciplinaridade 
remete à ideia de práticas que vão além da disciplinaridade. As autoras Fernanda Morillo, Maria Bordons e Isabel Gómez declaram que:

As definições mais comumente aceitas vêm da OCDE [Organização para a Cooperação e Desenvolvimento Econômico] (1998), na qual multidisciplinaridade, interdisciplinaridade e transdisciplinaridade são usadas para se referir a um nível crescente de interação entre disciplinas. Assim, na pesquisa multidisciplinar o assunto estudado é abordado de diferentes ângulos, usando diferentes perspectivas disciplinares, e não é realizada a integração entre elas. A pesquisa interdisciplinar leva à criação de uma identidade teórica, conceitual e metodológica, assim resultados mais coerentes e integrados são obtidos. Finalmente, a transdisciplinaridade vai um passo além e se refere a um processo no qual a convergência entre as disciplinas é observada e acompanhada por uma integração mútua das epistemologias disciplinares. (MARTINO; BOAVENTURA, 2013, p.3 apud MORILLO; BORDONS; GÓMEZ, 2003, p.1237)

José Luiz Fiorin (2008) acrescenta ainda que os pesquisadores não fazem mais a distinção entre multidisciplinaridade e pluridisciplinaridade. Ambos os termos passaram a remeter ao estudo de um mesmo objeto sob a abordagem de vários campos, de forma paralela e independente. Já a interdisciplinaridade demanda que os investigadores de áreas distintas transfiram conceitos teóricos e metodológicos e sejam capazes de promover a interseção das disciplinas. A título de exemplo, o sociólogo Pierre Bourdieu se valeu de conhecimentos da economia na elaboração de conceitos, como capital cultural e bens de cultura. No que diz respeito à transdisciplinaridade, a proposta é de fusão e diluição das fronteiras disciplinares. Nesse caso, Fiorin cita a ecologia, que se constituiu de saberes diversificados.Convém dizer que esse novo tratamento à pesquisa visa a transcender a territorização científica, centrada no objeto, na matéria e deixando à margem o ser humano.

No que diz respeito à vertente interdisciplinar humanística no Brasil, encontram-se, como principais representantes Hilton Japiassu, IvaniFazenda e Georges Gusdorf. Este último declara que:

Os sábios modernos deveriam buscar em comum a restauração das significações humanas do conhecimento [...]. É preciso restaurar a aliança da ciência com a sabedoria [...]. A significação fundamental da interdisciplinaridade é a de uma chamada à ordem do humano, de um humanismo da pluralidade e da convergência. (GUSDORF, 1977, p.37) 
Ao defender a necessidade de restaurar a relação entre ciência e sabedoria, o pensador francês Georges Gusdorf (1977) faz alusão ao fato de que, ao longo da história, filósofos estudiosos em geral adotavam uma postura interdisciplinar em face do conhecimento, tendo sido perdida essa tradição a partir do século XX. Sobre esse relato, vale comentar que o autor, inicialmente, nos leva a reavaliar a imagem da interdisciplinaridade como um pensamento revolucionário, que muitos pesquisadores e entidades, como a Unesco e a OCDE, tentam transmitir, sobretudo no campo das ciências sociais.

Contudo, ao versar sobre a LA, o presente estudo mostrou seu caráter interdisciplinar. Aliás, este trecho de Moita Lopes remete a um comentário sobre o reencantamento pela interdisciplinaridade na atualidade:

A questão da interdisciplinaridade, que se tornou quase um dos truísmos em epistemologias contemporâneas, já era apontada na LA nos anos 80 , embora seja necessário reconhecer que fosse sempre mais defendida como plataforma do que de fato executada. Havia e ainda há uma preponderância de teorização linguística, agora principalmente de uma linguística do discurso, o que já me levou a dizer que na LA temos "interdisciplinaridade, pero no mucho!".

(MOITALOPES, 2006, p.20)

Com relação à formação de especialista, deve-se dizer que a angústia de Gusdorf é compartilhada por um número expressivo de cidadãos, que vêm se questionando sobre o tratamento impessoal que recebem nos consultórios, hospitais, escolas etc. Cada profissional se restringe à sua especialidade e desconsidera o ser humano como um todo, desprezando sua realidade, sua história. Para essa vertente, o trabalho interdisciplinar se revela como a melhor solução para recuperar os valores humanistas perdidos na atualidade.

Como principais expoentes da vertente social-crítica estão Glaudêncio Frigotto, Norberto J. Etges, Roberto Follarir e Antônio Joaquim Severino. Eles reconhecem a relevância da interdisciplinaridade, sobretudo no universo das ciências sociais e da educação, no qual tudo está subordinado ao ser humano e às suas relações sociais. Além disso, dadas a complexidade humana e a magnitude de desafios impostos ao ser humano na atualidade, o acesso ao conhecimento vai solicitar cada vez mais do pesquisador, de maneira natural, a busca de saberes, de mediações em outros campos e de mudanças no plano epistemológico (FRIGOTTO, 2011).

Todavia, é necessário dizer que o surgimento da vertente social-crítica provém da objeção à concepção de interdisciplinaridade da corrente humanista. A principal crítica diz respeito ao 
fetichismo sobre a interculturalidade, ou seja, vê-la como a salvação de todos os males e desconsiderar o contexto histórico-social no qual a sociedade está inserida.

De acordo com Jantsch e Bianchetti (2011), a ideologia capitalista perpassa todas as esferas sociais, não há como negligenciar esse fato. Acrescentam ainda que essa vertente peca por atribuir aos sujeitos o poder absoluto na construção do conhecimento e do pensamento, como se eles fossem capazes de salvar o mundo com ajuda de parcerias. Todavia, os autores advertem que os trabalhos em "equipe" podem ser tão ou mais fragmentados que os realizados individualmente. O tipo de modalidade de trabalho não é fator determinante para estabelecer uma visão mais totalitária de um problema e menos alienante.

Ainda sobre a vertente humanista, Porto e Almeida a definem como:

Uma perspectiva humanista e pedagógica, para propor a busca de um diálogo ecumênico e reflexivo entre as várias áreas do conhecimento, centrando a transformação numa mudança de espírito dos próprios pesquisadores e do sistema de ensino. (PORTO; ALMEIDA, 2002, p. 337)

A enunciação reforça a concepção dessa vertente de que o ato de trabalhar com o público, o sujeito, precisa de diálogo, de interação. No âmbito da educação, as relações professor-aluno, aluno-aluno e professor-educador se mostram fundamentais para que se possam avaliar melhor os conhecimentos de que os alunos são detentores e aqueles que ainda precisam da mediação dos educadores para serem alcançados. No entanto, é primordial que todos estejam conscientes do contexto político-econômico-social na preparação dos conteúdos, dos planos de aulas, das propostas pedagógicas etc. Existe uma realidade social fora e dentro do estabelecimento escolar que precisa ser avaliada e refletida no espaço escolar, na sala de aula.

A respeito da vertente da complexidade, um de seus principais expoentes é o pensador francês Edgar Morin, o criador da teoria da complexidade. Porto e Almeida destacam que essa terceira tendência

Possui como característica central uma crítica epistemológica à ciência contemporânea [moderna], a partir da incorporação da temática da complexidade e da perspectiva sistêmica, contribuindo para o aprofundamento teóricometodológico em torno das diferentes estratégias de integração disciplinar.(PORTO; ALMEIDA,2002, p. 338)

Sobre a teoria da complexidade, Morin (2002) define inicialmente que complexus significa um tecido construído em conjunto, cuja funcionalidade de todos os elementos depende da interação e da união de todas as partes. De acordo com o autor, a extração de um componente impede a complexidade. Transportando esse pensamento para a educação, compreende-se que ela não funciona e encontra-se estagnada porque o conhecimento foi dividido em disciplinas. 
Em sua obra Os sete saberes para a educação do futuro (2002), Morin coloca em questão a estrutura da atual educação enfatizando que seu buraco negro está na expressiva valorização do aspecto racional e em uma formação de cunho individualista. Como mudança, propõe uma formação que leve em conta a emoção, as incertezas, o sentimento de coletividade, de alteridade no atual cenário de globalização e informatização.

Nessa obra, ressalta que seu objetivo não é prescrever normas de como se deve ensinar, mas repensar a complexidade do conhecimento, seus paradoxos, suas congruências e incongruências no espaço escolar, a fim de que os sujeitos sejam mais sábios e hábeis para lidar com as incertezas do mundo pós-moderno. Frisa que o ser humano tem tendência a preservar suas teorias, pois teme o inesperado, que o desestabiliza e lhe exige a reavaliação das ideias. De acordo com o autor, a educação do futuro deve estimular o posicionamento crítico, autocrítico, não apenas do sujeito em relação à sociedade, ao mundo externo, mas também os mitos, as crenças e as concepções racionalizadoras, que cegam os indivíduos e os imobilizam.

Em suma, compreende que:

O conhecimento especializado é uma forma particular de abstração. A especialização "abs-trai", por outras palavras, extrai um objeto do seu contexto e do seu conjunto, rejeita os laços e as intercomunicações com o seu meio, insereo num setor conceitual abstrato que é o da disciplina compartimentada, cujas fronteiras quebram arbitrariamente a sistemicidade (relação de uma parte com o todo) e a multidimensionalidade dos fenômenos; conduz a uma abstração matemática que opera em si mesma uma excisão com o concreto, privilegiando tudo quanto é calculável e formalizável. (MORIN, 2002, p. 46)

Convém dizer que tais ideologias morinianas se fazem presente nos projetos pedagógicos, na atual orientação pedagógica da perspectiva acional (PA), a qual passou a predominar sobre as outras abordagens e metodologias no ensino- aprendizado de FLE. Para a PA, o sujeito aprendiz é concebido como ator social, que deve dominar conhecimentos comunicativos e não comunicativos (saber-ser, saber-fazer, saber-conviver, saber-aprender).

Nessa perspectiva, o sistema escolar e o professor devem propor situações-problema aos alunos com as quais eles possam se deparar no dia a dia. Seguindo essa linha de pensamento, os legados culturais, conhecimentos científicos, conteúdos acumulados ao longo da história, fulcrais para que os sujeitos possam refletir sobre o presente, o futuro e entender melhor sua própria existência e a do mundo, perdem espaço em nome de uma "realidade". 
Cabe ainda enfatizar que as orientações pedagógicas sobre o projeto vêm descaracterizando o sentido desta atividade no âmbito escolar ao limitá-lo à simples execução de tarefas, bem como atrela ao professor um papel mecanicista. A aplicabilidade de um projeto em sala de aula não se centra em um fazer; mas sim, implica que os envolvidos, alunos e professores, tenham uma postura de pesquisador, capazes de mobilizar teoria e prática. No caso do professor, em especifico, ele deverá atuar com um orientador, sugerindo novas fontes de pesquisas aos seus alunos-pesquisadores e ajudá-los a aceder ao conhecimento almejado.

Sobre o "aprender a aprender", Newton Duarte faz tal declaração:

[...] O lema "aprender a aprender", ao contrário de ser um caminho para a superação do problema, isto é, um caminho para uma formação plena dos indivíduos, é um instrumento ideológico da classe dominante para esvaziar a educação escolar destinada à maioria da população, enquanto, por outro lado, são buscadas formas de aprimoramento da educação das elites. (DUARTE, 2000, p.43)

Para Libâneo (2009), o papel da educação deve ser o de promover a interação entre o conhecer, o fazer, o ser e o criticar. Sabe-se que a escola não tem a capacidade de tudo transformar, mudar; contudo, sua atuação de maneira crítica pode ser concebida como uma forma de reação às injustiças, de luta por uma sociedade mais igualitária e, por conseguinte, mais democrática.

No que diz respeito à ciência, ainda que ela não seja capaz de dar ao homem todas as respostas, soluções a sua angústia e tenha cometidos erros, suas contribuições ao longo da história não podem ser negligenciadas. É oportuno frisar que as pesquisas científicas permitiram ao ser humano se questionar, intervir no mundo, na sua vida e renegar o fatalismo determinista dos fatos. Nas reflexões de Morin, os males da humanidade recaem sobre a ciência, sobre o pensamento racional.

Segundo Duarte (2011), o ponto recorrente no pensamento pós-moderno consiste em anunciar uma crise da ciência, dos paradigmas da razão. Com base em Marilena Chauí, o autor faz uma síntese de como é apresentada a crise do pensamento pós-moderno.

- Negação de que haja uma esfera da objetividade. Esta é considerada um mito da razão, em seu lugar surge a figura da subjetividade narcísica desejante;

- Negação de que a razão possa propor uma continuidade temporal e captar o sentido imanente da história. O tempo é visto como descontínuo, a história é 
local e descontínua, desprovida de sentido e necessidade, tecida pela contingência;

- Negação de que a razão possa propor captar núcleos de universalidade no real. A realidade é constituída por diferenças e alteridades, e a universalidade é um mito totalitário da razão;

- Negação de que o poder se realiza à distância do social, através de instituições que lhe são próprias e fundadas tanto na lógica da dominação quanto na busca da liberdade. Em seu lugar existem micro poderes invisíveis e capilares que disciplinam o social. (p.90)

Como comentários finais sobre o pensamento moriniano, não se pode deixar de observar que, embora suas orientações pareçam responder às angústias da atualidade e ser transformadoras, elas vão ao encontro dos interesses políticos, econômicos, ideológicos de quem detém o poder em nossa sociedade, bem como geram um certo sentimento de fracasso humano. O autor não faz uma crítica pertinente sobre as acentuadas desigualdades econômicas e sociais presentes em determinados países e sociedades. Sua "neutralidade" política distorce, naturaliza o processo de desumanização do ser.

Frigotto contesta a concepção de delimitação de um objeto de investigação como um procedimento de fragmentação arbitrária, asseverando que

A compreensão da categoria totalidade concreta em contraposição à totalidade caótica, vazia, é imprescindível para entendermos a interdisciplinaridade como necessidade imperativa na construção do conhecimento social. A totalidade concreta, como nos adverte Kosik (1978), não é tudo e nem é a busca do princípio fundador de tudo. Investigar dentro da concepção da totalidade concreta significa buscar explicitar, de um objeto de pesquisa delimitado, as múltiplas determinações e mediações históricas que o constituem. A historicidade dos fatos sociais consiste fundamentalmente na explicitação da multiplicidade de determinações fundamentais e secundárias que os produz. (FRIGOTTO, 2011, p.37)

Frigotto salienta ainda que a produção do conhecimento precisa do sujeito, que, embora busque esgotá-lo em sua totalidade, é limitado. O conhecimento humano é sempre relativo, parcial e incompleto. Além disso, embora a interdisciplinaridade permita, sobretudo ao campo das ciências sociais, tornar seu objeto de investigação mais concreto e complexo, diminuindo, assim, o grau de relatividade e imprecisão, a autora chama a atenção para o fato de que as propostas trans/interdisciplinares têm como principal obstáculo a atual materialidade histórica, que fragmenta o sujeito por meio da dominação, da alienação e da exclusão. 
Sobre o movimento interdisciplinar para a produção e a socialização do conhecimento, é necessário destacar que o desejo de ruptura com o paradigma precedente parece estar se sobrepondo à realidade e à razão humana. Os procedimentos utilizados para a mediação do conhecimento precisam ser avaliados em função do contexto histórico, da situação e dos sujeitos envolvidos. Tomar a interdisciplinaridade como solução para todos os males das ciências naturais, das ciências sociais e da educação significa adotar uma postura tão ou mais positivista. Não se questiona o fato de que a investigação nas ciências sociais com a interação de outras disciplinas permite ao pesquisador um conhecimento mais concreto de seu objeto; porém, o que chama a atenção é a tentativa de mascarar suas limitações.

\section{Considerações finais}

A dicotomia entre teoria e prática no ensino-aprendizagem de LE parece ser explicada por sua própria história, que se constituiu, sobretudo, apoiada nos pilares de uma epistemologia da prática. Se no período do estruturalismo isso se expressava nitidamente, no pósestruturalismo/pós-modernismo observa-se uma dissimulação desse pragmatismo. Ao analisar as fundamentações teóricas, as orientações de ensino e os discursos de determinados pensadores, constata-se que não há uma preocupação em formar sujeitos críticos que reflitam sobre o cenário educativo e proponham transformações, de fato, na história. As "mudanças" propostas surgem apenas como uma adequação às novas necessidades do mercado.

Quanto à interdisciplinaridade, cumpre dizer que seu enfoque epistemológico e pedagógico ainda está em processo de construção. Existem apenas definições imprecisas sobre o que é a interdisciplinaridade e uma fundamentação teórico-metodológica que parece desconsiderar a materialidade histórica. A teoria da complexidade moriniana, ao visar ao todo, pode promover a superficialidade do conhecimento, gerando, assim, um conhecimento ainda mais fragmentado.

Como afirma Frigotto (2011), o conhecimento de maneira mais totalizante de si e do mundo só é possível quando os fatores histórico-materiais e culturais são contemplados na formação do sujeito. Independentemente da pluri/trans/interdisciplinaridade e de todos os outros tipos de mediação do conhecimento, a negligência da materialidade histórica, de modo (in)consciente, aponta para uma ação pedagógica que pode contribuir para a alienação humana. 
No que diz respeito ao ensino de LE, em específico de FLE, parece essencial destacar que o professor precisa conhecer as ideologias subjacentes às orientações metodológicas no processo de ensino-aprendizagem. Tal postura não apenas lhe daria mais autonomia no processo de ensinoaprendizagem, mas também, agiria para contrapor e questionar determinadas teorias desse campo, que tentam lhe impor um papel tecnicista.

\section{Referências}

ALMEIDA, G. Pra que somar se a gente pode dividir? Abordagens integradoras em saúde, trabalho, meio ambiente. Dissertação (Mestrado em Saúde Pública) — Escola Nacional de Saúde Pública, Fundação Oswaldo Cruz, Rio de Janeiro, 2000.90f.

ALMEIDA FILHO, J. C. P. de. Dimensões comunicativas no ensino de línguas. 5. ed. Campinas: Pontes, 2008.

$$
\text { O professor de língua estrangeira em formação. 3. ed. Campinas: Pontes, } 2009 .
$$

ALMEIDA FILHO, N. Interssetorialidade, transdisciplinaridade e saúde coletiva: atualizando um debate em aberto. Revista de Administração Pública, Rio de Janeiro, v. 34, n. 6, p. 11-34, nov./dez. 2000.

. Transdisciplinaridade e saúde coletiva. Ciência e Saúde Coletiva, Rio de Janeiro, v. 11, n. 1-2, 1997.

BRASIL. Ministério da Educação. Parâmetros curriculares nacionais: língua estrangeira. Brasília, 1998.

. Secretaria de Educação Média e Tecnologia. Parâmetros curriculares nacionais: ensino médio. Brasília: MEC/Semtec, 2002.

CONTRERAS,D.J.La autonomíaDel professorado. Madrid:Moreto, 1997.

CUQ, J. P.; GRUCA, I. Cours de didactique du français langue étrangère et seconde. Grenoble: PUG, 2002.

DELORS, J. Educação: um tesouro a descobrir. Relatório da Comissão Internacional sobre a Educação para o Século XXI. Unesco, Ministério da Educação e Cultura. São Paulo: Cortez, 1998.

DUARTE, N. Vigotski e o “aprender a aprender": crítica às apropriações neoliberais e pósmodernas da teoria vigotskiana. Campinas: Autores Associados, 2000. 
ETGES, N.J. Ciência, interdisciplinaridade e educação. In: JANTSCH, A. P.; BIANCHETTI, L. (Org.). Interdisciplinaridade: para além da filosofia do sujeito. 8. ed. Petrópolis: Vozes, 2011. p. 51-84.

FACCI, M. G. D. Valorização ou esvaziamento do trabalho do professor? Um estudo crítico-comparativo da teoria do professor reflexivo, do construtivismo e da psicologia vigotskiana. Campinas: Autores Associados, 2004.

FIGUEIREDO, F.J.Q. Aprendendo com os erros: uma perspectiva comunicativa de ensino de línguas. Goiânia: UFG,1997.

FIORIN, J. L. Linguagem e interdisciplinaridade.Revista Alea, Rio de Janeiro,v. 10, n.11, p.11-34, nov./dez. 2008.

FONTORA, A. Diretrizes e bases da educação nacional: introdução, crítica, comentários, interpretação. Rio de Janeiro: Aurora, 1968.

FREIRE, P. Ação cultural para a liberdade e outros escritos. Rio de Janeiro: Paz e Terra, 1975. . Pedagogia do oprimido. Rio de Janeiro:Paze Terra, 1970.

FRIGOTTO, G. A interdisciplinaridade como necessidade e como problema nas ciências sociais. In: JANTSCH, A. P.; BIANCHETTI, L. (Org.).Interdisciplinaridade: para além da filosofia do sujeito. 9. ed. Petrópolis:Vozes, 2011.p. 25-49.

GALISSON, R. D'hier à aujourd'hui:la didactique générale des langues étrangères du structuralisme au fonctionnalisme. Paris: CLEInternational, 1991.

; PUREN, C. La formation en question. Paris: CLE International, 2001.

GRIGOLETTO, M. Leituras sobre a identidade: contingência, negatividade e invenção. In: MAGAlHÃES, I.; GRIGOLETTO, M.; CORACINI, M. J. (Org.). Práticas identitárias: língua e discurso. São Paulo:Claraluz, 2006.

GUSDORF, G. Passé, présent, avenir de la recherche interdisciplinaire.Revue Internationale de Sciences Sociales, Paris, v. 29, n. 4, p. 627-648, 1977.

IMBERNÓN, F. (Org.).Educação no século XXI: os desafios do futuro imediato.Tradução de Ernani Rosa. Porto Alegre: Artmed, 1999.

JANTSCH, A. P. Concepção dialética de escrita-leitura: um ensaio. In: BIANCHETTI, L. (Org.). Trama e texto: leitura crítica e escrita criativa. São Paulo: Plexus, 1996. v. 1,p. 37-55.

;BIANCHETTI, L. Imanência, história e interdisciplinaridade. In: (Org.). Interdisciplinaridade: para além da filosofia do sujeito. 9.ed.atual.e ampl. Petrópolis: Vozes, 2011. 
JAPIASSU, $\mathrm{H}$. A atitude interdisciplinar no sistema de ensino.Tempo Brasileiro, Rio de Janeiro, n. 108, p. 83-94, jan./mar. 1992.

JIMENEZ, S.; MENDES, M. Erradicar a pobreza e reproduzir o capital: notas críticas sobre as diretrizes para a educação do novo milênio. Cadernos de Educação, Pelotas:

FAE/PPGE/UFPEL, n. 28, p. 119-137, jan./jun. 2007.

LEÃO, A. C. O ensino de línguas vivas. São Paulo: Companhia Editora Nacional, 1935. especial, jan. 2003.

LIBÂNEO, J. Democratização da escola pública: a pedagogia crítico-social dos conteúdos. 23. ed. São Paulo: Loyola, 2009.

. Pedagogia e pedagogos, para quê?. 3. ed. São Paulo: Cortez, 2000.

Reflexividade e formação de professores: outra oscilação do pensamento pedagógico brasileiro?. In: PIMENTA S.M.; GHEDIN, E. (Org.).Professor reflexivo no Brasil: gênese e crítica de um conceito. 2.ed. São Paulo: Cortez, 2002.

MARTINO, L.C.; BOAVENTURA, K. T.O mito da interdisciplinaridade: história e institucionalização de uma ideologia. Revista da Associação Nacional dos Programas de Pósgraduação em Comunicação, Brasília: E-compós, v.16, n.1, jan./abr. 2013.

MARTINS, L. M. Análise do processo de personalização de professores. Tese (Doutorado) — Faculdade de Filosofia e Ciências, Universidade Estadual Paulista, Marília, 2001. 276 f.

MOITA LOPES, L. P. Oficina de linguística: a natureza social e educacional dos processos de ensino/aprendizagem de línguas. Campinas: Mercado de Letras, 1996.

(Org.). Por uma linguística aplicada indisciplinar. São Paulo: Parábola, 2006.

MORILLO, F; BORDONS, M; GÓMEZ, I. Interdisciplinarity in Science: A Tentative Typology of Disciplines and Research Areas. Journal of theAmerican Society for Information Science andTechnology, v. 54, n. 13, p. 1237-1249, 2003.

MORIN, E. Os sete saberes paraa educação do futuro. São Paulo: Cortez, 2002.

PERRENOUD, P. Construir as competências desde a escola. Porto Alegre: Artmed, 1999. . Práticas pedagógicas, profissão docente e formação. Lisboa: Dom Quixote, 1993.

PORTO, M. F. de S.; ALMEIDA, G. E. S. de. Significados e limites das estratégias de integração disciplinar: uma reflexão sobre as contribuições da saúde do trabalhador. Ciência e Saúde Coletiva, Rio de Janeiro, v. 7, n. 2, p. 335-347, 2002. 
PUREN, C. Continuités, ruptures et circularités dans l'évolution de la didactique des langues étrangères en France. Études de Linguistique Appliquée,Paris: Didier Érudition, n. 78, p. 6574, abr./jun. 1990.

RELATÓRIO PARA A UNESCO DA COMISSÃO INTERNACIONAL SOBRE EDUCAÇÃO PARA O SÉCULO XXI. Educação: um tesouro a descobrir. 4.ed. São Paulo:Cortez; Brasília: MEC/Unesco, 2000.

SAVIANI, D. A nova lei da educação: trajetória, limites e perspectivas. Campinas: Autores Associados, 1997. 